\title{
Characteristics of drowning victims in a surf environment: a 6-year retrospective study in southwestern France
}

Éric Tellier ${ }^{1,2,3^{*}}$ (D) Bruno Simonnet ${ }^{3}$, Cédric Gil-Jardiné ${ }^{1,2,3}$, Bruno Castelle ${ }^{4}$, Marion Bailhache $e^{1,2,5}$ and Louis-Rachid Salmi ${ }^{1,2,6}$

\begin{abstract}
Background: Drowning is the third cause of non-intentional injury death worldwide. Beaches of Gironde, in southwestern France, are exposed to strong environmental conditions, leading to rip currents and shore breaks. Bathing season usually lasts from April to October and is supervised from June till mid-September. The objective of this study was to study the characteristics of drowning victims along Gironde surf beaches and to identify peculiarities compared to national figures.

Methods: All calls originating from beaches to the emergency call center of Gironde from 2011 to 2016 were analyzed. Patient data, filled by a physician based on information given by pre-hospital care team (lifeguards, paramedics or emergency physicians), were extracted from the emergency call center database. We used Szpilman classification ( $0=$ rescue to $6=$ cardiac arrest) to assess severity. Rescues are patients without respiratory impairment who needed lifeguards or helicopter intervention. We compared our findings with national studies carried every three years (2012 and 2015).

Results: We analyzed 5680 calls from beaches and included 4398, 576 of which were rescued from the water, including 352 without respiratory impairment (stage 0). Among drownings, 155 had cough only (stage 1), 26 pulmonary rales (stage 2), 9 pulmonary edema (stage 3) and 1 had pulmonary edema with hypotension (stage 4). Five rescued people were in respiratory arrest and 28 were in cardiac arrest. $77.5 \%$ were bathers, others were mainly surfers or body-boarders. Drowning victims median age was 24 (quartiles: 17-40), and sex-ratio was 1.44 Male/ Female. Men were significantly older than women (34 vs. 26 years old), and severity from stage 1 to 4 was positively associated with age. Compared to national data, Gironde drownings had a higher proportion of 15-44 year-old victims, and the case-fatality was lower in Gironde (11.5\%) than at the national level $(27.4 \%, p<0.001)$.

Conclusion: Along Gironde coast, drowning is rarely severe, concerns mostly young men; the age distribution could explain the different case-fatality. Further study is needed to identify environmental predictors of drowning.
\end{abstract}

Keywords: Drowning, Epidemiology, Natural hazard

\footnotetext{
*Correspondence: eric.tellier@u-bordeaux.fr

'INSERM, ISPED, Bordeaux, France

2Univ. Bordeaux, ISPED, Bordeaux, France

Full list of author information is available at the end of the article
}

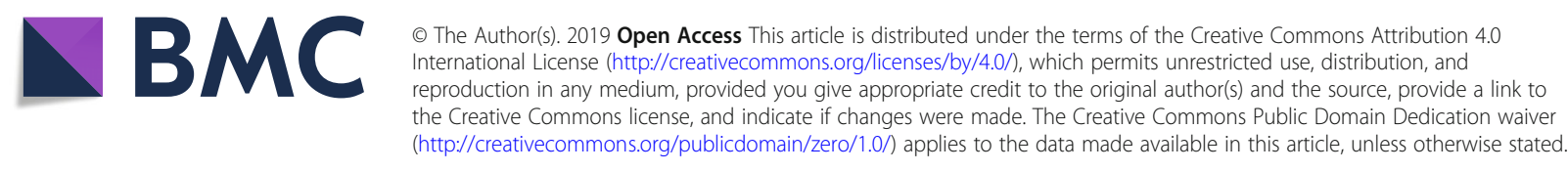




\section{Background}

Drowning is defined in 2005 by the World Health Organization (WHO) as "the process of experiencing respiratory impairment from submersion/immersion in liquid" (van et al., 2005). It is the third leading cause of non-intentional injury death worldwide, representing in 2017 294,000 people according to the Global Burden of Disease data (Dicker et al., 2018).

In France, every three years, a national study is conducted by the French national institute of public health (Santé Publique France), registering all cases of drowning leading to hospitalization or death, from June, 1st till September, 30th. During 2015, this study reported 1266 drownings (fatal and non-fatal) in France, including 637 $(50.3 \%)$ on coasts (Lasbeur et al., 2016); data were similar in the 2012 report (Lasbeur \& Thélot, 2013). Studied coasts are highlighted in the overall map of Fig. 1 (Corsica not shown). On the beaches of Gironde, an area in Southwestern France, magnified in Figs. 1, 38 drownings resulting in 7 deaths were reported in the 2015 study.

Drowning is associated with both environmental and individual factors, and occurs quickly. Although few interventions have been evaluated, prevention is considered key to improve beachgoers behavior in specific environmental conditions and hopefully reduce drownings (Bierens, 2006; Hatfield et al., 2012; Sherker et al.,
2010; Szpilman et al., 2012). Once drowning occurs, a chain of survival implies a fast response with paramedics and a medical team if needed (Dyson et al., 2013; Salomez \& Vincent, 2004; Szpilman et al., 2014). Indeed, watched areas needed less medical attention and cardiopulmonary resuscitation for victims of drowning (Szpilman, 1997; Venema et al., 2010).

The sandy coast of Gironde is exposed to high-energy waves. This leads to a ridge and runnel system inducing rip currents (Castelle et al., 2007). These conditions can be encountered in other parts of the world, and it is known that most beach-related drowning are caused by rips (Castelle et al., 2018; Gensini \& Ashley, 2010; Morgan et al., 2008).

The Gironde coast comprises $126 \mathrm{~km}$ of sandy surf beaches. Because it is a major touristic destination in southwestern France, beach safety is an important concern. During the high season, from mid-June to mid-September, major beaches are watched by lifeguards from 11:00 AM to 7:00 PM. Some of the busiest beaches are watched from the beginning of June, but bathing season can begin in April and last till the end of October when warm weather conditions prevail. Drowning prevention is done essentially within guarded areas, through signage at the beach entrances and distribution of leaflets describing rip-current and shore-break hazards which are the primary surf zone hazards along this

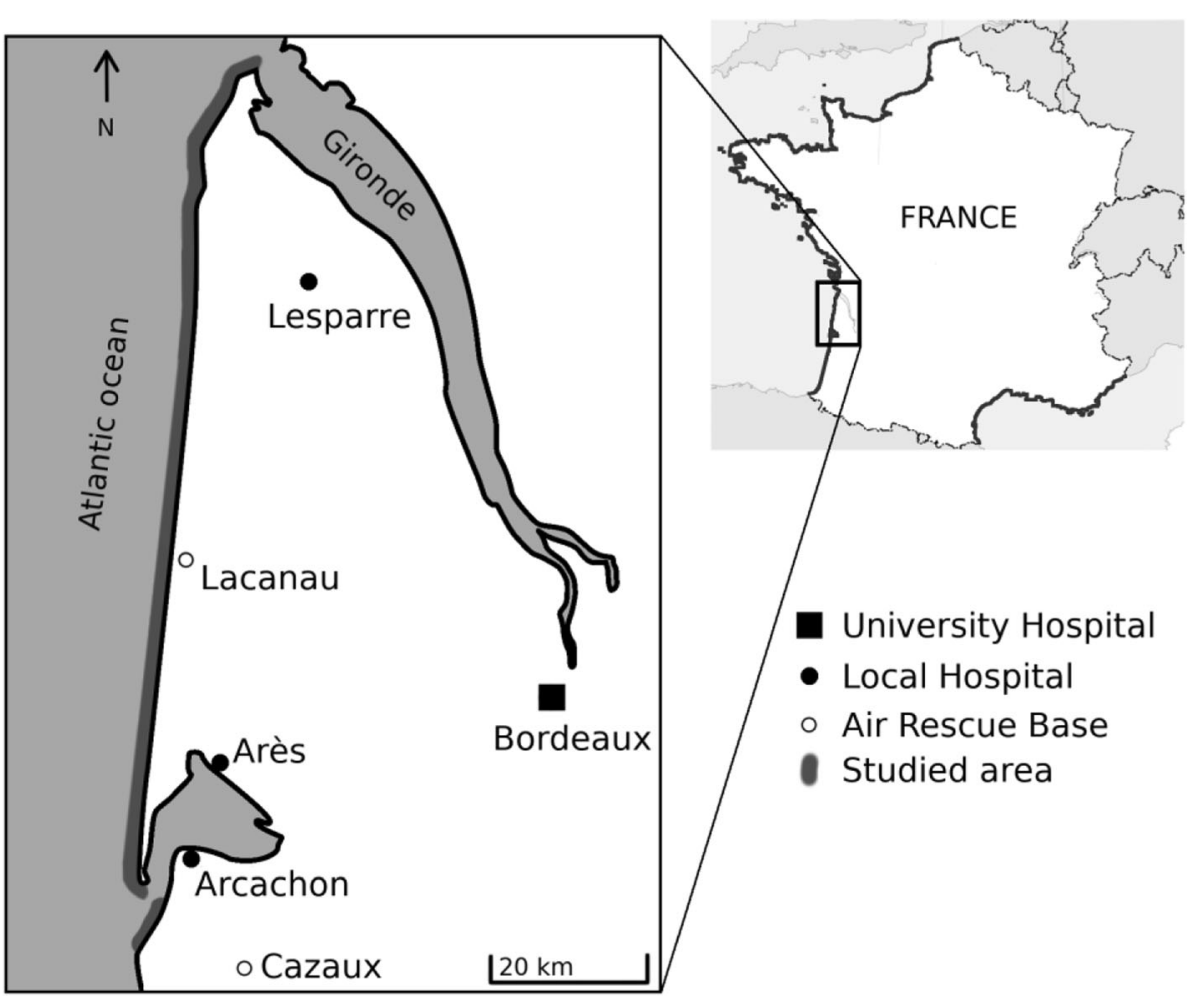

Fig. 1 Map of Gironde, south western France, with description of the studied area and nearby hospitals 
stretch of coast. During the high season, two helicopters are available for sea rescue.

Describing the drowning problem at a local and regional level is an essential step to develop effective prevention countermeasures (van et al., 2005; Idris et al., 2003; World Health Organization, 2014). There is a need of documenting history and description of victims in that particular environment. Moreover, as drowning occurs quickly, people rescued by lifeguards need to be taken into account, even if the absence of severe drowning stage did not lead to hospitalization.

The objective of our study was to characterize drowning victims in the oceanic coast of Gironde and to identify peculiarities compared to national figures.

\section{Methods}

\section{Data source and inclusion criteria}

During summer, lifeguard interventions for rescue from water is followed by a call to the Medical Emergency Call Center. This center also receives direct calls from beachgoers. This retrospective study was based on data from emergency calls coming from Gironde beaches from January 1st, 2011 to December 31st, 2016. As we were interested in drownings occurring in strictly surf environment, calls from the beaches inside the Arcachon lagoon (Fig. 1) were excluded. Collecting every call from beaches, even those unrelated to drowning, is also interesting as a previous, unpublished, work carried out in 2003 in Gironde reported a strong correlation during summer between beach attendance and number of calls for any reasons coming from beaches (Murcott, 2003).

All medical emergency calls from beachgoers or lifeguards come to a Medical Emergency Call Center (SAMU, Service d'Aide Médicale d'Urgence). For each call, a physician fills the database with information given by callers, and paramedics and pre-hospital care teams when involved. We excluded calls without victim, trainings and duplicates. Contents of all calls were reviewed by the first author, a junior epidemiologist with training in emergency medicine. We then classified all calls in two groups, drowning cases and other calls.

\section{Variables and data collection}

We collected location, date and time of the call, gender and age of the victim for all medical emergency calls from beaches. For drownings, we collected the medical history of the victim, activity (bathing, surf, bodyboard, other), initial status given by lifeguards report, and discharge status (left on site, transferred to emergency department or intensive care unit, death on site, death at hospital). The severity of drowning was rated, from the first clinical description reported, with the Szpilman classification (Table 1). Stage zero, or rescue, characterizes people who need to be rescued from water, but
Table 1 Short description of drowning stages, according to Szpilman classification (Szpilman et al., 1997 and 2012)

\begin{tabular}{ll}
\hline Stage & Symptomatology \\
\hline 0 (rescue) & None \\
1 & Cough, normal pulmonary auscultation \\
2 & Cough, rales in some pulmonary fields \\
3 & Acute pulmonary edema with normal blood pressure \\
4 & Acute pulmonary edema, hypotension or shock \\
5 & Respiratory arrest and/or coma \\
6 & Cardiac arrest \\
\hline
\end{tabular}

without cough. Stage 1 is defined by the presence of cough, stage 2 victims present pulmonary rale in some fields; stage 3 have pulmonary edema and stage 4 present pulmonary edema with hypotension. Stage 5 are patient with respiratory arrest without cardiac arrest and stage 6 is cardiac arrest. Stages from 2 to 6 need to be hospitalized while stage 1 can be left under surveillance of lifeguards. When available, we recorded resources such as helicopter or jet-ski used to rescue the victim. Finally, location of event (in or out bathing area, beach location) was recorded.

We assumed that stage- 0 and -1 victims without hospital transfer had a favorable outcome. Outcomes of the most severe victims (stage 2 and over) were collected from the files of Intensive Care Units were patients were admitted. National data, collected every three years, were extracted reports of the national institute of public health, Santé Publique France, carried in 2012 and 2015 (Lasbeur et al., 2016; Lasbeur \& Thélot, 2013). Those data are gathered using hospital (emergency and pre-hospital care services) and emergency call center reporting of drownings leading to hospitalization (including emergency evaluation) or death.

\section{Statistical analysis}

We first compared calls for rescue and drowning with other calls to characterize the studied population. We then compared our findings on drownings to national data. To describe drowning victims, qualitative variables were reported as percentages and numbers. Quantitative variables were reported as medians and inter-quartile range. Fisher and permutation tests were used to assess differences among groups for qualitative and quantitative variables respectively. As spatial distribution of accesses to the beaches is discontinuous and mostly depends on municipal boundaries, continuous spatial data analysis was not possible, and we divided the coast into 9 areas (from A to I in Fig. 1) according to those boundaries.

We calculated univariate odds ratios of drowning occurrence among calls between low- and high-seasons, between weekdays and weekend and between locations. Data analysis was done with the $\mathrm{R}$ software and coin 
package (R Core Team, 2017; Harrell, 2014; Harrell, 2015; Hothorn et al., 2008).

\section{Results}

\section{Emergency calls and their characteristics}

We screened 5680 call files, of which 1282 were excluded (Fig. 2). For calls secondary to rescue from water, age was missing in 170 files (29.5\%), mostly for stages $0(n=164)$ and $1(n=6)$ patients. Missing data concerned helicopter interventions for air-lifting operations where, usually, only the number of involved patients, their severity, and sometimes sex are filled. Median age was 24years (mean 30.9, quartiles: 17-45) among people rescued from water and 23 years among other calls (mean 28.4, quartiles: 15-40). Compared to other beach-related calls, the sex-ratio was not different $(p=0.88)$. Males rescued from water were older than for other beach-related injuries $(p<0.001)$, but female victims were similar in age $(p=0.06)$.

Sex was available for 427 cases (74.1\%) and most victims were stages $0(61.1 \%)$ and 1 (26.9\%) (Table 2). Other calls $(n=3822)$ were mostly secondary to medical cause, beach-related trauma, but there were specific surf injuries such as shore-break related injuries (17.7\%) and envenomation (5\%) (Table 3). Among calls secondary to rescue from water, most patients were males $(\mathrm{M} / \mathrm{F}=$ 1.44) and the severity was not different in males and females (Fig. 3, $p=0.14$ ). Males were significantly older than females (mean 34 vs. 26 years, $p<0.001$ ). Age varied across stages, independently of $\operatorname{sex}(p=0.001)$

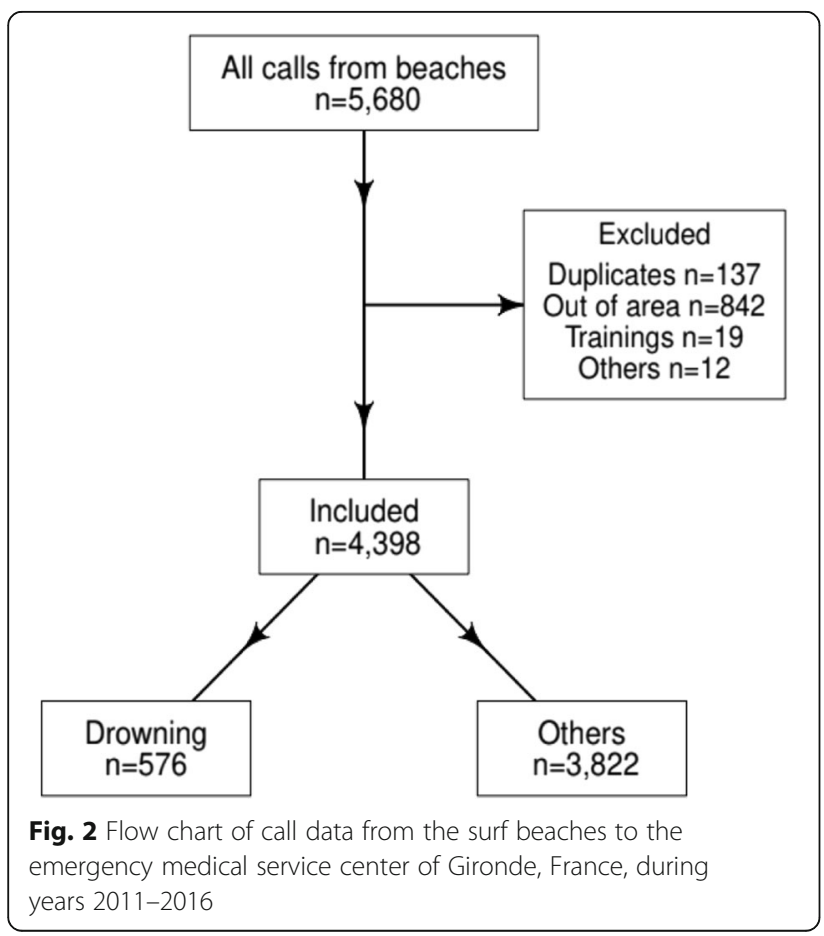

Table 2 Population characteristics of calls secondary to rescue from water $(n=576)$ along Gironde surf beaches, 2011 to 2016. Severity was assessed according to the Szpilman classification (Szpilman et al., 2012)

\begin{tabular}{|c|c|c|}
\hline Variable & $\mathrm{N}$ & $\%$ \\
\hline \multicolumn{3}{|l|}{ Sex } \\
\hline Female & 175 & 30.4 \\
\hline Male & 252 & 43.6 \\
\hline Missing & 149 & 26.0 \\
\hline \multicolumn{3}{|l|}{ Severity } \\
\hline 0 (Rescue) & 352 & 61.1 \\
\hline 1 & 155 & 26.9 \\
\hline 2 & 26 & 4.5 \\
\hline 3 & 9 & 1.6 \\
\hline 4 & 1 & 0.02 \\
\hline 5 & 5 & 0.9 \\
\hline 6 & 28 & 4.9 \\
\hline \multicolumn{3}{|l|}{ Outcome } \\
\hline Left on site & 363 & 63.0 \\
\hline Death & 20 & \\
\hline \multicolumn{3}{|l|}{ Evacuated } \\
\hline University hospital & 20 & 3.5 \\
\hline Death & 4 & \\
\hline Local hospital & 163 & 28.3 \\
\hline Other hospital & 2 & \\
\hline Missing & 8 & \\
\hline \multicolumn{3}{|l|}{ Activity } \\
\hline Bathing & 444 & 77.5 \\
\hline Body board & 11 & 1.9 \\
\hline Surf & 24 & 4.2 \\
\hline Other & 3 & 0.5 \\
\hline Missing & 91 & 15.9 \\
\hline
\end{tabular}

(Fig. 3). Low- and high-season drownings were not different in age distribution, but a higher proportion of males were victims during low season (Odds Ratio (OR) $2.4295 \%$ confidence interval (CI) [1.39-4.31], $p<0.001$ ).

A medical history was explicitly noted for 49 cases (8.5\%), reporting mainly cardio-vascular diseases $(n=$ $17)$, asthma $(n=13)$, and psychiatric disorders $(n=5)$; one patient had a history of epilepsy. The absence of medical history was documented in 112 cases (19\%). Therefore, 415 patients $(72.0 \%)$ were without reporting medical history. Alcohol consumption was notified in 2 cases. No drowning occurred within bathing area during the study period.

Compared to national data, Gironde drownings had a higher proportion of 15-44 year-old victims and a lower proportion of people above 45 and below 5 (Fig. 4). The 
Table 3 Population characteristics of emergency calls excluding victims of drowning from Gironde surf beaches, 2011 to 2016 $(n=3822)$

\begin{tabular}{|c|c|c|}
\hline Variable & $\mathrm{N}$ & $\%$ \\
\hline \multicolumn{3}{|l|}{ Sex } \\
\hline Female & 2133 & 55.8 \\
\hline Male & 1673 & 43.8 \\
\hline Missing & 16 & 0.4 \\
\hline Shore-break related injuries & 675 & 17.7 \\
\hline Shoulder & 177 & \\
\hline Neck & 177 & \\
\hline Back & 96 & \\
\hline Knee & 96 & \\
\hline Head & 42 & \\
\hline other & 87 & \\
\hline Envenomation & 191 & 5.0 \\
\hline Weevers & 117 & \\
\hline Jellies & 25 & \\
\hline Physalia physalis & 34 & \\
\hline Missing & 15 & \\
\hline Dislocation & 235 & 6.1 \\
\hline Wounds & 525 & 13.7 \\
\hline Other trauma & 1059 & 27.7 \\
\hline Miscellaneous Other Medical & 959 & 25.1 \\
\hline Seizure & 35 & 0.9 \\
\hline Missing & 146 & 3.8 \\
\hline \multicolumn{3}{|l|}{ Activity } \\
\hline Bathing & 282 & 9.0 \\
\hline Body board & 88 & 2.8 \\
\hline Surf & 769 & 24.4 \\
\hline Other seashore activity & 39 & 1.2 \\
\hline Activity on the beach & 907 & 28.8 \\
\hline Missing & 1062 & 33.7 \\
\hline
\end{tabular}

case-fatality was lower in Gironde than at the national level $(11.5 \%$ vs $27.4 \%, \mathrm{p}<0.001)$.

\section{Drowning timing and location}

With 118 rescues from water and drowning events reported at the emergency call center with 556 calls for other beach-related events, there were significantly more rescues leading to a call in 2014 than in other years (Table 4). Over six years, the number of drownings varied depending on whether the day was a weekday, a weekend or a holiday. During the low-season, the probability that a call concerned a drowning case was increased on weekdays (OR 3.11; 95\% CI 2.07-4.62) even though 7 deaths occurred on weekends and 2 during weekdays in low season. Adjusted to the other calls, the low season was riskier than the high season (OR 1.98; 95\% CI 1.54-2.52).

The proportion of drowning among emergency calls was lower in area I than in other locations (OR 0.31; 95\% CI 0.19-0.47). Areas G and $\mathrm{H}$ had a significant higher incidence than other locations (Table 3).

\section{Discussion}

To our knowledge, this is the first study that characterizes precisely the burden of drowning in a high-risk area, taking into account both rescues and off-season drownings. The latter do not usually appear in lifeguard registries as they work only during high-season (mid-June to the end of August for most stations). This study is the first step to prevention, analyzing existing data in a specific context (World Health Organization, 2017) to define and orient targeted prevention strategies, according to WHO and CDC recommendations (World Health Organization, 2017; Doll et al., 2007). Such data collection could be done in other area for comparison.

Our study has some limits related to the retrospective use of existing medical files. Although records of the Emergency Call Center are useful to identify drownings needing medical advice or helicopter interventions, they miss rescues by lifeguards that did not lead to a call for medical advice. Local regulation requires lifeguards to report all victims, but it is known that there are missed cases as some local annual unpublished reports, show a higher number of rescues than our study. Therefore, one has to be careful when making external comparison because the number of calls is only an indirect estimation of the denominator. Further, Medical Emergency Call Center files were not always documenting medical history and circumstances of drowning. They were still filled well enough to assess initial severity of drowning.

Data collection of beach-related injuries, including drowning, is challenging (Williamson, 2006). We tried to access to local data, but they are incomplete or very scarce, reporting only total numbers of rescue for a given day for example. Thus, we do not have any sources on demographics of bathers. Following this study, the identified need for a better documentation led to the development of a specific questionnaire, which was distributed to Gironde lifeguards at the start of the 2018 season.

Men were less represented than in most epidemiological studies (Gensini \& Ashley, 2010; Claesson et al., 2014; Claesson et al., 2012; Clemens et al., 2016; Harada et al., 2011; Quan et al., 2014), but the male/female ratio is consistent with other oceanic studies (Szpilman et al., 2014; Doll et al., 2007; Williamson, 2006; Claesson et al., 2012). In our study, drowning victims were mostly adolescents and young adults, with very few children. This low proportion of children compared to other drowning 


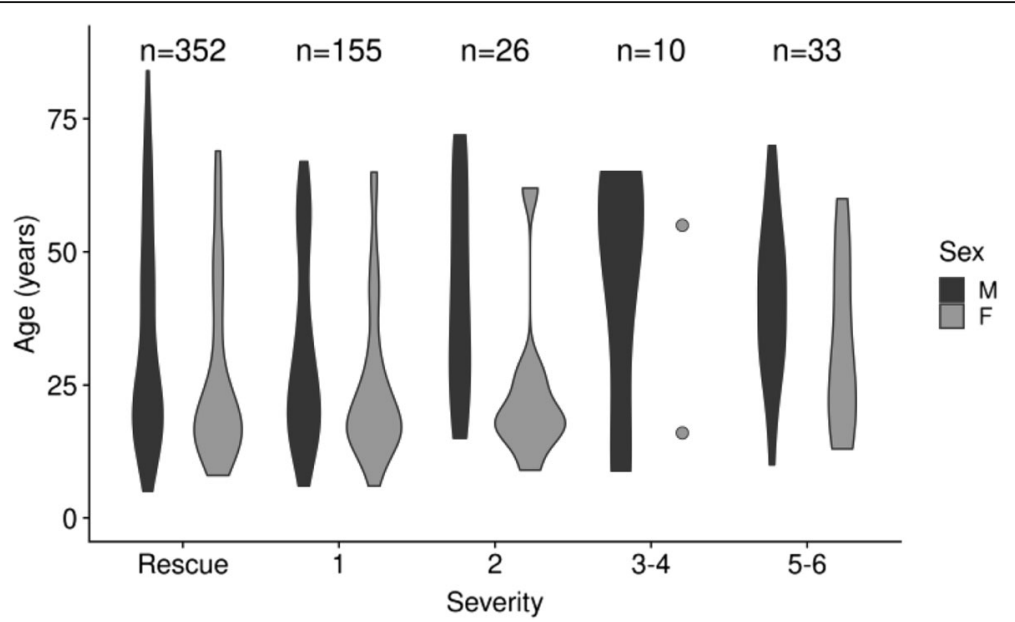

Fig. 3 Age of drowning victims according to sex and severity, Gironde surf beaches, 2011-2016. Width is proportional to number of individuals in group at a given age. Only 2 females were reported for stages 3 or 4

epidemiological studies might be due to a lower exposure: they may be more likely under supervision of a parent, or less exposed to surf beaches as lakes are common in the area. Indeed, most studies do not focus on surf environment. Nevertheless, this age distribution is not surprising given the wave conditions, with frequent shore breaks; the age distribution is similar to findings in Hawaii (Williamson, 2006) and Canada (Doll et al., 2007). Compared to other calls, people rescued from water were older, especially among males. This could be explained by a riskier behavior among adult males. In Australia, similar findings have been reported regarding the propensity to swim outside flagged area (Sherker et al., 2010), and death rate among surf beach swimmer population (Morgan et al., 2008).
The comparison to national data shows that the surf environment has a particular population and suggests a need to identify geographical disparities along the coastline. Compared to other coastal areas contributing to national data, Gironde is known to be a place with many rip current occurrences and strong shore-break waves. Those hazards can be found in all other coasts of France, but with much less frequency and intensity. Water temperature is generally lower than along Mediterranean coasts, and higher than in Brittany and northern coasts. Air temperatures are similar to Mediterranean coasts. Unfortunately, we do not have similar studies to compare demographics of victims in other places, but the demographic distribution could explain the difference of death rates between national and regional data.

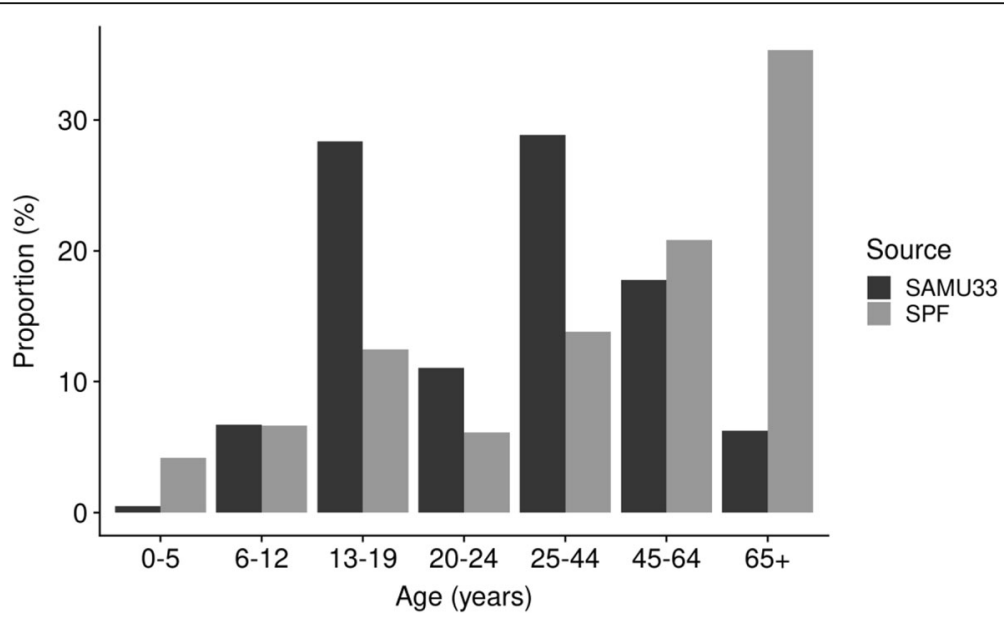

Fig. 4 Comparison of age of drowning victims who needed a hospitalization or died, from the database of Gironde Emergency Call Center, years 2011-2016 (SAMU33, $n=188$ ) and along all coasts of France (SPF, data from Santé Publique France, French national institute of public health, reports of 2012 and $2015, n=1165$ ) 
Table 4 Characteristics of drownings compared with other calls from beaches of Gironde, by type of day, year, and location with odds ratio (OR) and 95\% confidence intervals

\begin{tabular}{|c|c|c|c|c|c|}
\hline \multicolumn{2}{|l|}{ Variable } & Other calls & Drownings & OR & $95 \% \mathrm{Cl}$ \\
\hline \multicolumn{6}{|c|}{ Type of day } \\
\hline & Holiday & 52 & 11 & 1.41 & $0.66-2.75$ \\
\hline & Week-end & 205 & 44 & 1.46 & $1.02-2.06$ \\
\hline & Weekdays & 87 & 40 & 3.20 & $2.12-4.76$ \\
\hline & High season & 3.478 & 481 & 0.50 & $0.39-0.65$ \\
\hline \multicolumn{6}{|l|}{ Year } \\
\hline & 2011 & 670 & 88 & 0.85 & $0.66-1.08$ \\
\hline & 2012 & 708 & 116 & 1.11 & $0.88-1.39$ \\
\hline & 2013 & 617 & 70 & 0.72 & $0.54-0.94$ \\
\hline & 2014 & 556 & 118 & 1.51 & $1.20-1.90$ \\
\hline & 2015 & 664 & 88 & 0.86 & $0.67-1.10$ \\
\hline & 2016 & 607 & 96 & 1.06 & $0.83-1.35$ \\
\hline \multicolumn{6}{|c|}{ Location } \\
\hline & A & 292 & 40 & 0.90 & $0.62-1.28$ \\
\hline & B & 105 & 20 & 1.27 & $0.74-2.09$ \\
\hline & C & 337 & 46 & 0.90 & $0.64-1.24$ \\
\hline & D & 161 & 26 & 1.07 & $0.67-1.65$ \\
\hline & E & 293 & 58 & 1.35 & $0.98-1.82$ \\
\hline & $\mathrm{F}$ & 1217 & 160 & 0.82 & $0.67-1.00$ \\
\hline & G & 199 & 51 & 1.77 & $1.26-2.45$ \\
\hline & $\mathrm{H}$ & 760 & 152 & 1.44 & $1.17-1.77$ \\
\hline & I & 458 & 23 & 0.31 & $0.19-0.47$ \\
\hline Total & & 3.822 & 576 & & \\
\hline
\end{tabular}

We could not differentiate locals from tourists, which could imply a different prevention strategy, but previous studies along southwestern coast of France reported a majority of non-locals but few foreigners (Castelle et al., 2018). Nevertheless, other studies suggest a higher risk of drowning among non-residents (Williamson, 2006). Severity of drowning was correlated with age in stages 1 to 4 , but not for the severe stages 5 and 6 , which is consistent with other studies (Dyson et al., 2013; Quan et al., 2014; Morgan \& Ozanne-Smith, 2013; Suominen et al., 2002). Our data did not allow studying predictive factors of outcome.

The total number of beachgoers and bathers is unknown, thus precluding estimating the actual exposure. To compensate for this lack of denominator data, Gensini et al. suggested using the number of deaths by 100-km segments of coastline (Gensini \& Ashley, 2010). Dividing the US coastline in $100-\mathrm{km}$ segments to examine rip-current fatalities, they found the highest risk in eastern Florida, with 46 fatalities in 14 years for $100 \mathrm{~km}$. This gives a normalized yearly rate of 3.3 deaths $/ 100 \mathrm{~km}$. In our study, the normalized death year ratio in Gironde would be 3.2 deaths $/ 100 \mathrm{~km}$, showing a risk equivalent to the highest observed in the U.S.A. Further studies are needed to measure the number of beachgoers and bathers and therefore provide a better denominator to estimate the incidence of drowning.

Most victims were rescues and stage 1, with few medical needs, although they needed lifeguards and, sometimes, helicopter interventions. As drowning occurs quickly, those victims need the same focus of prevention than the others. Missing cases would very likely concern rescues or stage 1 . Our study is a first step to collect data from this population. In the absence of adequate exposure estimations, a prevention strategy targeting the whole population and not only the most severe cases, might be more feasible and effective.

Several results can help us orient a possible prevention strategy. Most drownings occurred during high season but, adjusted to the other calls, low seasons and weekdays showed more calls for drowning or people rescued from water. This could be due to lifeguards prevention which is a major activity (Koon et al., 2018), or a bias concerning the other calls. On the other hand, hot weather is known to be associated with drowning (Dyson et al., 2013). Therefore, prevention messages should be more reinforced in the absence of lifeguards, and lifeguard presence could be adapted.

Alcohol appeared in very few cases $(0.3 \%)$, compared to other studies (Szpilman, 1997). This could be a reporting bias, but also explained by the fact that most beaches are in remote areas and are unlikely to be frequented after sunset.

The number of calls is an indirect measure of the denominator, but further work is needed to ensure the comparisons between years and seasons. Year 2014, with a higher proportion of calls concerning rescues from water, is an outlier. To our knowledge, there were no difference in lifeguard headcount, nor in safety campaigns, and weather data from MétéoFrance showed normal summer temperatures, except a cold end of August. This difference could be explained by winter storms and spring weather that can fundamentally change the shape of the beach and therefore the occurrence of rip currents (Castelle et al., 2016).

The spatial distribution of drownings along the Gironde surf coast also shows some interesting significant disparities. The higher risk of areas $\mathrm{G}$ and $\mathrm{H}$ could be due to the proximity with the metropolitan area of Bordeaux, with a higher exposure. Another explanation is the difference of watching conditions between municipalities, as there can be twice as many lifeguards per kilometers of beach in a given area than in another. A missing parameter is the proportion of rescues within the bathing area, but our data show that all deaths occurred outside these watched areas. 
Geographic disparities are a supplementary strong argument for rip current hazards: area I, less exposed to waves, had the lowest incidence of rescue from water among calls. This could not be explained by difference in beach access (it is near a city) neither by the amount of lifeguards (comparable to area $\mathrm{H}$ ). As rip currents are driven by wave and tide conditions (Castelle et al., 2016; Bruneau \& Castelle, 2009), a future study is needed to explore the link between rescues and environmental parameters.

\section{Conclusion}

This observational study in an area with specific hazards identified the demographics of drowning victims and led to the development of a specific questionnaire to improve reporting. This study revealed notable differences with national data and suggests that drownings along coastline must be studied at a local scale. The studied area is at high-risk of rip-related drowning and there is a need to identify days at risk using meteorological, wave and tide parameters. Such a study could lead to a prevention tool for lifeguards and emergency managers.

\section{Abbreviations}

CDC: Center for Disease Control; Cl: Confidence Interval; OR: Odds Ratio; SAMU: Service d'Aide Médicale Urgente (emergency medical service); WHO: World Health Organization

\section{Acknowledgements}

None.

\section{Funding}

None.

\section{Availability of data and materials}

The datasets generated and/or analyzed during the current study are not publicly available due to restriction from the French National Committee for the Protection of Data Privacy, but are available from the corresponding author on reasonable request.

\section{Authors' contributions}

ET and BS collected data, ET analyzed data, MB and CGJ provided statistical advice. LRS supervised the findings of this work. ET wrote the manuscript with support of CGJ, LRS and BC and all authors contributed substantially to its revision. All authors take responsibility for the paper as a whole. All authors read and approved the final manuscript.

\section{Ethics approval and consent to participate}

Data collection was declared to the French National Committee for the Protection of Data Privacy (CNIL, Comission Nationale de I'Informatique et des Libertés), with restriction to publish aggregated data. As a retrospective observational study design, no authorization from an ethic committee was needed according to French law.

\section{Consent for publication}

Not applicable.

\section{Competing interests}

$E T, B S, M B, B C, C G J$ and LRS report no competing interest.

\section{Publisher's Note}

Springer Nature remains neutral with regard to jurisdictional claims in published maps and institutional affiliations.

\section{Author details}

${ }^{1}$ INSERM, ISPED, Bordeaux, France. ${ }^{2}$ Univ. Bordeaux, ISPED, Bordeaux, France. ${ }^{3} \mathrm{CHU}$ Bordeaux, Pôle Urgences Adultes-SAMU-SMUR, place Amélie Raba-Léon, 33076 Bordeaux, CEDEX, France. ${ }^{4}$ CNRS, UMR EPOC, Univ. Bordeaux, Bordeaux, France. ${ }^{5} \mathrm{CHU}$ de Bordeaux, Pôle de Pédiatrie, 33076 Bordeaux, France. ${ }^{6} \mathrm{CHU}$ de Bordeaux, Pôle de santé publique, Service d'information médicale, 33076 Bordeaux, France.

Received: 22 January 2019 Accepted: 25 March 2019

Published online: 13 May 2019

\section{References}

Bierens J. Handbook on Drowning. In: JJLM B, editor. . Berlin Heidelberg: Springer-Verlags; 2006. p. 714

Bruneau N, Castelle B. Field observations of an evolving rip current on a mesomacrotidal well-developed inner bar and rip morphology. Cont Shelf Res. 2009;29:1650-62.

Castelle B, Bonneton P, Dupuis $H$, Sénéchal N. Double bar beach dynamics on the high-energy meso-macrotidal French Aquitanian coast: a review. Mar Geol. 2007;245(1-4):141-59.

Castelle B, Brander R, Tellier E, Simonnet B, Scott T, McCarroll J, et al. Surf zone hazards and injuries on beaches in SW France. Nat Hazards. 2018;93(3):1317-35.

Castelle B, Scott T, Brander RW, McCarroll RJ. Rip current types, circulation and hazard. Earth-Sci Rev. 2016;163:1-21.

Claesson A, Lindqvist J, Herlitz J. Cardiac arrest due to drowning-changes over time and factors of importance for survival. Resuscitation. 2014;85(5):644-8.

Claesson A, Lindqvist J, Ortenwall P, Herlitz J. Characteristics of lifesaving from drowning as reported by the Swedish fire and rescue services 1996-2010. Resuscitation. 2012;83(9):1072-7.

Clemens T, Tamim H, Rotondi M, Macpherson AK. A population based study of drowning in Canada. BMC Public Health 2016 Jul; 16:559.

Dicker D, Nguyen G, Abate D, Abate KH, Abay SM, Abbafati C, et al. Global, regional, and national age-sex-specific mortality and life expectancy, 19502017: a systematic analysis for the global burden of disease study 2017. Lancet. 2018;392(10159):1684-735.

Doll LS, Bonzo SE, Sleet DA, Mercy JA, editors. Handbook of Injury and Violence Prevention [Internet]. Boston, MA: Springer US; 2007 [cited 2019 Mar 5]. Available from: http://link.springer.com/10.1007/b136518.

Dyson K, Morgans A, Bray J, Matthews B, Smith K. Drowning related out-ofhospital cardiac arrests: characteristics and outcomes. Resuscitation. 2013;84(8):1114-8.

Gensini VA, Ashley WS. An examination of rip current fatalities in the United States. Nat Hazards. 2010;54:159-75.

Harada SY, Goto RS, Nathanson AT. Analysis of lifeguard-recorded data at Hanauma Bay, Hawaii. Wilderness Environ Med. 2011;22(1):72-6.

Harrell FE. rms: Regression Modeling Strategies [Internet]. 2014. Available from: http://CRAN.R-project.org/package=rms.

Harrell , FE. Regression Modeling Strategies [Internet]. Cham: Springer International Publishing; 2015 [cited 2019 Feb 1]. (Springer Series in Statistics). Available from: http://link.springer.com/10.1007/978-3-319-19425-7.

Hatfield J, Williamson A, Sherker S, Brander R, Hayen A. Development and evaluation of an intervention to reduce rip current related beach drowning. Accid Anal Prev. 2012;46(0):45-51.

Hothorn T, Hornik K, van de WMA, Zeileis A. Implementing a class of permutation tests: the coin package. J Stat Softw. 2008;28(8):1-23.

Idris AH, Berg RA, Bierens J, Bossaert L, Branche CM, Gabrielli A, et al. Recommended guidelines for uniform reporting of data from drowning: the "Utstein style". Circulation. 2003;108:2565-74.

Koon W, Rowhani-Rahbar A, Quan L. The ocean lifeguard drowning prevention paradigm: how and where do lifeguards intervene in the drowning process? Inj Prev. 2018;24(4):296-9.

Lasbeur L, Szego-Zguem E, Thélot B. Surveillance épidémiologique des noyades Enquête NOYADES 2015. 1er juin - 30 Septembre 2015 [Internet]. SaintMaurice : Santé publique France; 2016. Available from: www. santepubliquefrance.fr

Lasbeur L, Thélot B. Surveillance épidémiologique des noyades - Enquête NOYADES 2012. 1er juin - 30 septembre 2012. Saint-Maurice: Institut de veille sanitaire; 2013.

Morgan D, Ozanne-Smith J. Surf lifeguard rescues. Wilderness Environ Med. 2013;24(3):285-90. 
Morgan D, Ozanne-Smith J, Triggs T. Descriptive epidemiology of drowning deaths in a surf beach swimmer and surfer population. Inj Prev. 2008;14:62-5.

Murcott $\mathrm{O}$. Intérêt de la mise en place au SAMU 33 d'une régulation estivale spécifique pour les urgences sur les plages [Unpublished medical thesis]. [Angers, France]: Université d'Angers; 2003.

Quan L, Mack CD, Schiff MA. Association of water temperature and submersion duration and drowning outcome. Resuscitation. 2014;85(6):790-4.

$R$ Core Team. R: a language and environment for statistical computing [internet]. Vienna, Austria: R Foundation for Statistical Computing; 2017. Available from: https://www.R-project.org/

Salomez F, Vincent J-L. Drowning: a review of epidemiology, pathophysiology, treatment and prevention. Resuscitation. 2004;63(3):261-8.

Sherker S, Williamson A, Hatfield J, Brander R, Hayen A. Beachgoers' beliefs and behaviours in relation to beach flags and rip currents. Accid Anal Prev. 2010:42(6):1785-804

Suominen P, Baillie C, Korpela R, Rautanen S, Ranta S, Olkkola KT. Impact of age, submersion time and water temperature on outcome in near-drowning. Resuscitation. 2002;52(3):247-54.

Szpilman D. Near-drowning and drowning classification: a proposal to stratify mortality based on the analysis of 1,831 cases. Chest. 1997;112(3):660-5.

Szpilman D, Bierens JJLM, Handley AJ, Orlowski JP. Drowning. N Engl J Med. 2012;366(22):2102-10.

Szpilman D, Webber J, Quan L, Bierens J, Morizot-Leite L, Langendorfer SJ, et al. Creating a drowning chain of survival. Resuscitation. 2014;85(9):1149-52.

van BE, Branche CM, Szpilman D, Modell JH, Bierens J. A new definition of drowning: towards documentation and prevention of global public health problem. Bull World Health Organ. 2005;83(11):801-80.

Venema AM, Groothoff JW, Bierens JJLM. The role of bystanders during rescue and resuscitation of drowning victims. Resuscitation. 2010;81(4):434-9.

Williamson A. Feasibility study of a water safety data collection for beaches. J Sci Med Sport. 2006;9(3):243-8.

World Health Organization. Global report on drowning: preventing a leading killer [internet]: World Health Organization; 2014. Available from: http://www.who.int/ entity/violence_injury_prevention/global_report_drowning/en/index.html

World Health Organization, editor. Preventing drowning: an implementation guide. Geneva: World Health Organization; 2017. p. 105

Ready to submit your research? Choose BMC and benefit from:

- fast, convenient online submission

- thorough peer review by experienced researchers in your field

- rapid publication on acceptance

- support for research data, including large and complex data types

- gold Open Access which fosters wider collaboration and increased citations

- maximum visibility for your research: over $100 \mathrm{M}$ website views per year

At $\mathrm{BMC}$, research is always in progress.

Learn more biomedcentral.com/submissions 